\title{
An accelerated nutrition transition in Iran
}

\author{
Hossein Ghassemi $^{1}$, Gail Harrison ${ }^{2, *}$ and Kazem Mohammad ${ }^{3}$ \\ ${ }^{1}$ National Study on Food and Nutrition Security in Iran, 18/2 Pasarghad Building, Shahrak Ghods, Tehran, Iran: \\ ${ }^{2}$ School of Public Health, 36-081 Center for Health Sciences, University of California at Los Angeles, 10833 Le Conte \\ Avenue, Los Angeles, CA 90095, USA: ${ }^{3}$ Department of Biostatistics and Epidemiology, School of Public Health, \\ Tehran University of Medical Sciences, Tehran, Iran
}

\begin{abstract}
Objective: To describe the emergence of the nutrition transition, and associated morbidity shifts, in the Islamic Republic of Iran.

Design: Review and analysis of secondary data relating to the socio-political and nutritional context, demographic trends, food utilisation and consumption patterns, obesity, and diet-related morbidity.

Results and conclusions: The nutrition transition in Iran is occurring rapidly, secondary to the rapid change in fertility and mortality patterns and to urbanisation. The transition is occurring against the backdrop of lack of sustained economic growth. There is considerable imbalance in food consumption with low nutrient density characterising diets at all income levels, over-consumption evident among more than a third of households, and food insecurity among 20\% of the population. Obesity is an emerging problem, particularly in urban areas and for women, and both diabetes and other risk factors for heart disease are becoming significant problems.
\end{abstract}

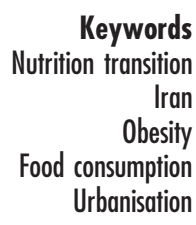

The nutrition transition in Iran is taking place in the context of rapid demographic change, urbanisation and social development, but in the absence of steady and significant economic growth. Problems of malnutrition and micronutrient deficiencies still dominate the public health nutrition agenda; however, there is evidence that obesity and its related morbidities are emerging as potentially serious problems at the same time. Food consumption patterns and dietary quality are highly income-dependent, but dietary choices, particularly in higher-income groups, are also driven by non-economic forces. Rapid urbanisation has led to significant decreases in physical activity. National policies are based on principles of self-sufficiency in food, social equity and poverty alleviation. The development of a nutritionally literate population is emerging as a priority not only for the control of malnutrition but also for prevention of a potential epidemic of obesity-related chronic disease.

\section{The socio-political and economic context}

The Islamic Revolution of 1979 began an era that forms the context for the demographic, health and nutrition transitions that are currently underway in Iran. Following the revolution, there was a period of relatively rapid reorganisation of institutions and social policies, with the goal of forming a society governed by Islamic principles of social justice and equity. Policies and institutions were structured to invest heavily in making basic services and amenities, including infrastructure (roads, electricity, safe water), education, primary health care services, staple foodstuffs and social security, available to the entire population. Rural development and the extension of basic services to remote rural areas were particularly emphasised. Over the ensuing 22 years, substantial gains have been made in health and education. Life expectancy has increased by 12 years to 67 years; infant and under-five mortality rates have been halved to 26 and 33 per 1000 live births, respectively; and maternal mortality has decreased dramatically. Childhood immunisation coverage is almost universal, and basic health services are available to almost all of the population. Adult literacy in 1998 was 75\% (67.4\% for women). School enrolment at the primary level was 90\% for the population as a whole in 1997 with almost equal rates for boys and girls; secondary school enrolment was $81 \%$ (76\% for girls $)^{1-3}$.

The economic situation contrasts sharply with the social gains over the same period. The eight-year war with Iraq (1980-1988) resulted in substantial human and material losses, and a protracted period of recovery. The 1986 downturn in oil prices resulted in a significant economic shock to an economy already in recession, and the trade restrictions imposed by the USA also had a negative impact ${ }^{4}$. Household income and expenditures in real terms declined dramatically during the late 1980s, particularly in urban households, and remain at depressed levels; see Fig. 1 for trends in household food expenditures over this period. The last several years have seen some economic recovery, but Iran remains a lower middle-income country, with a per capita gross domestic product (GDP) of just under $\$ 1300^{4}$. The contrasting pictures of social development and economic 


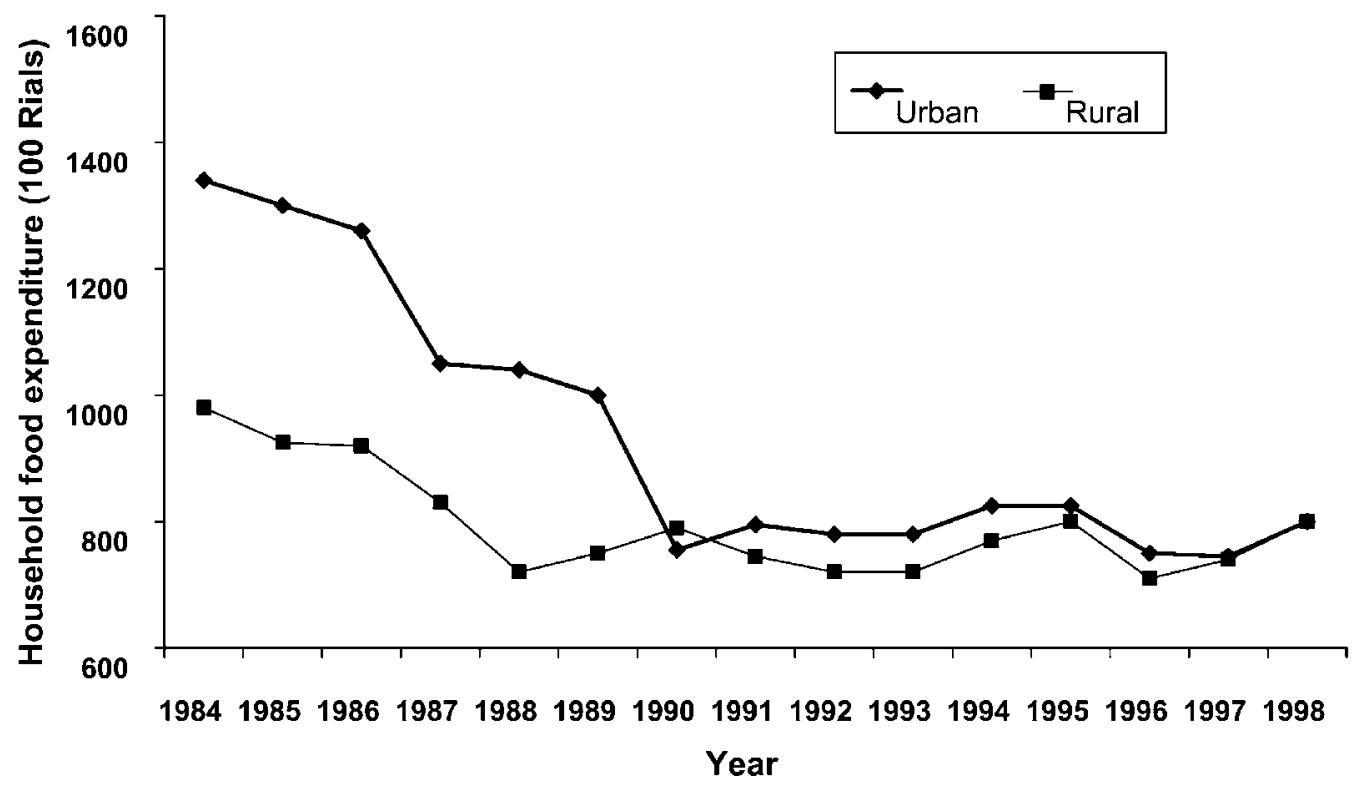

Fig. 1 Household food expenditure (100 Rials)

stagnation are summarised in Table 1, which shows trends in GDP and in the Human Development Index (HDI). The latter is a composite index showing cumulative impacts of education, survival and income - in the case of Iran the improvement in HDI from 0.566 in 1975 to 0.706 in 1998 is accounted for by gains in the health and education arenas. For comparison, per capita GDP for all developing countries rose from US\$ 720 in 1975 to US\$ 3260 in 1998 and the HDI for all developing countries in 1998 was $0.642^{5,6}$.

In spite of policies designed to promote social equity, there is substantial inequality of income distribution in Iran today, with families in the highest decile of per capita income having 15-20 times the income of families in the lowest decile 7 . It is estimated that $17 \%$ of the population lives below the official poverty line, and a conservative estimate is that 10 to $14 \%$ of the workforce is unemployed $^{4}$. Consumer price inflation has been high over the last several years, with the annual inflation rate averaging 24\% per year during the 1990-1995 period, peaking at $50 \%$ in $1995-6$ and decelerating to $18 \%$ in 1997-984. Food prices have risen at somewhat higher rates than the overall consumer price index ${ }^{3}$.

Agricultural policy in Iran, since the revolution, has been governed by the basic objective of self-sufficiency in food. Growth in food production over the last several

Table 1 Trends in the Human Development Index (HDI) and gross domestic product (GDP) per capita for Iran, 1975-1998

\begin{tabular}{llllll}
\hline & 1975 & 1980 & 1985 & 1990 & 1998 \\
\hline HDI & 0.566 & 0.573 & 0.618 & 0.653 & 0.706 \\
GDP per capita (1995 US\$) & 1511 & 1129 & 1208 & 1056 & 1275 \\
\hline
\end{tabular}

Sources: Ghassemi ${ }^{3}$, constructed from Human Development Report 20005; The World Bank ${ }^{6}$. years has exceeded growth in population, and selfsufficiency ratios were estimated in 1997 at about 80\% for wheat, 90\% for animal protein and 100\% for poultry, milk and cheese. Wheat, which accounts for $40 \%$ of the dietary energy supply and $45 \%$ of the total protein supply, saw a doubling in production between 1989 and 1996 in response to a comprehensive national wheat programme, which included input subsidies to producers as well as consumer subsidies on flour and bread ${ }^{4}$.

\section{Population and urbanisation}

Iran's population comprises about 60 million people, having approximately doubled twice over the last 40 years $^{1,3}$. The population growth rate rose from $2.7 \%$ in 1976 to a high of $3.2 \%$ in 1986 , reflecting a dramatic decrease in mortality, high fertility consistent with a pronatalist government policy in the early post-revolution years, and an influx of refugees from neighbouring countries. A major shift occurred, beginning in 1987, as policy makers began to come to grips with the predictable consequences of a continued high population growth rate and the limits to agricultural and other resources. At the same time, slow economic growth coupled with inflation meant that it was becoming more and more difficult for a large proportion of families to make ends meet. A conscious policy shift towards fertility control was made quite suddenly, and backed up with programmes to make family planning services available free of charge and accessible to all couples, even going so far as requiring couples applying for a marriage licence to participate in family planning education programmes. The economic situation and the high value placed on education for all children, by both government and families, provided a population very ready to change fertility-related 
Table 2 Population and urbanisation trends in Iran, 1955-1995

\begin{tabular}{llll}
\hline Trend & \multicolumn{1}{c}{1955} & \multicolumn{1}{c}{1975} & \multicolumn{1}{c}{1995} \\
\hline Total population & 18.9 million & 33.8 million & 60.1 million \\
Percentage urban & 31.4 & 47 & 61 \\
Number of urban centres & 186 & 373 & 615 \\
\hline
\end{tabular}

Source: Iran Statistical Center, 1996.

behaviour, and the fertility rate fell dramatically over a very short period. The population growth rate was estimated to be $1.4 \%$ in 1997 and the total fertility rate at 2.6, down from a high of 6.5 in the early $1970 \mathrm{~s}^{3}$. The population structure is currently very young with a large cohort of adolescents; as this cohort enters its reproductive years, in spite of low fertility, a new 'baby boom' is expected, and the total population is expected to be 100 million by the year 2020 .

More than $60 \%$ of Iran's population is currently urbandwelling (Table 2). The first wave of rural-to-urban migration occurred prior to the revolution, due to population pressure on land and a breakdown of the support system for tenant farmers. Rapid urbanisation continued throughout the 1970s and 80s. In 1976, there were just two cities with more than one million inhabitants (Tehran and Mashad); by 1996 there were five, with Isfahan, Tabriz and Shiraz all having passed the one million mark. Together these five large cities now account for more than 12 million of the population. Urban growth rates have decreased somewhat in the last decade (Table 3), but even so the population is projected to be almost 80\% urban-dwelling by the year 2020 .

\section{The nutritional background in Iran}

Iran has traditionally been a major endemic area for iodine deficiency disease (IDD) and iron deficiency anaemia has been, and continues to be, a major public health problem. Human zinc deficiency was first described in Iran and, although current data are lacking, likely remains a limiting nutrient in some circumstances. Clinical vitamin A deficiency has not been documented as a major problem, although intakes are low in poor households and subclinical deficiency has been found when looked for, and probably is quite common. Riboflavin deficiency has been repeatedly documented, at levels that are clinically evident, at least seasonally, in rural areas and is the most limiting micronutrient in terms of nutritional adequacy in food consumption data nation-wide. The riboflavin problem derives from limited diets among the poor and probably also from destruction of the vitamin in fresh and processed dairy products exposed to sunlight. Over the last several years there have been major efforts to provide iodised salt to the entire population, and IDD is rapidly disappearing $^{8}$. Efforts to combat other micronutrient deficiencies have been sporadic and thus far have not been very effective.

Malnutrition in pre-school children is still a significant problem. A 1995 Multiple Health Indicator Cluster Survey 9 estimated rates of stunting, underweight and wasting nationally to be $18.9 \%, 15.7 \%$ and $6.6 \%$, respectively, with rural children considerably more likely to be malnourished than urban ones. The recent National Health Survey ${ }^{10}$, conducted on a nationally representative sample in 1999, estimated rates of stunting and wasting among 25 year olds to be even slightly higher than the 1995 estimates (Table 4). A significant $29 \%$ of rural pre-school children are stunted, in spite of a relatively normal birth weight distribution and quite favourable breast-feeding practices, indicating that morbidity and diet in early childhood remain significant problems.

\section{Food consumption}

Data reflecting food consumption patterns are available at the household level from two major sources, in addition to small-scale studies. A national Household Budget and Expenditure Survey is carried out yearly and provides data on expenditures on foods by food group; these data have been available since the early 1970s. Secondly, a National Food Consumption Survey was carried out in 1995 by the National Nutrition Institute; the sample comprised more than 5000 households and was nationally representative. The data are household-level, and include a quantitative record of household food use for a period of three consecutive days.

The traditional Iranian diet is wheat-based, with a variety of relatively unrefined, unleavened, whole-wheat breads comprising the main staple. Rice is the other staple grain but, due both to social norms and to relative prices, comprises a larger portion of the diet for the higher socioeconomic classes than for the poor. Dairy products are consumed widely, mostly as yoghurt and fresh (not aged) cheese. A wide variety of fruits and vegetables are grown and consumed and meat, poultry and fish are highly valued, but relatively expensive. Nuts and fresh leafy greens, including plants used in other cuisines as herbs in small quantities, are consumed regularly and in quantities

Table 3 Growth of urban centres in Iran by source, 1920-1995

\begin{tabular}{lcccc}
\hline Urban growth & $1920-1960$ & $1961-1975$ & $1976-1985$ & $1986-1995$ \\
\hline Growth of urban population (\%) & 2.65 & 4.42 & 5.40 & 3.15 \\
From natural growth (\%) & 2.12 & 2.77 & 3.20 & 1.90 \\
From migration (\%) & 0.53 & 1.65 & 2.20 & 1.25 \\
\hline
\end{tabular}

Source: Iran Statistical Center, 1981 and 1996. 
Table 4 Prevalences (\%) of stunting, underweight, wasting and overweight among 2-5-year-old children; Iran National Health Survey, 1999

\begin{tabular}{lcc}
\hline & \multicolumn{2}{c}{ Prevalence (\%) } \\
\cline { 2 - 3 } Condition & Urban $(n=2588)$ & Rural $(n=1989)$ \\
\hline Stunted (height-for-age $Z$-score $\leq-2)$ & 20.0 \\
Boys & 17.6 & 29.3 \\
Girls & 14.0 & \\
Underweight (weight-for-age $Z$-score $\leq-2)$ & 22.9 \\
Boys & 17.7 & 14.2 \\
Girls & 9.5 & \\
Wasted (weight-for-height $Z$-score $\leq-2)$ & 12.3 \\
Boys & 11.3 & 12.0 \\
Girls & 11.0 & \\
Overweight (weight-for-height $Z$-score $\geq+2)$ & 6.9 \\
Boys & 9.0 & 7.3 \\
Girls &
\end{tabular}

that make important contributions to nutrient intake ${ }^{11}$. Tea is the major beverage. Untargeted consumer subsidies on food, put in place during the war with Iraq to secure minimum and equitable food supplies, have been reduced substantially over the last several years, but remain in place for bread, wheat flour and sugar. Additionally, subsidies in the form of ration coupons are utilised for vegetable oil, rice, meat and milk.

The Household Expenditure and Budget Survey data indicate that per capita dietary energy availability has increased from just over $2000 \mathrm{kcal}_{\text {person }}{ }^{-1}$ in 1970 to almost $3000 \mathrm{kcal}_{\text {person }}{ }^{-1}$ currently $^{3}$. Nevertheless, $20 \%$ of households are deemed food-insecure, in that they are estimated to have access to less than $90 \%$ of their dietary energy needs, and 11\% are severely food-insecure with access to $<80 \%$ of energy needs ${ }^{12}$. Dietary quality is problematic for a larger proportion of the population, with $30 \%$ of households consuming less than $80 \%$ of the requirement for calcium, 46\% for vitamin $\mathrm{A}$ and $70 \%$ for riboflavin $^{12}$. There is a sharp income dependence of the household food basket in terms of quality, with all but the lowest decile of households with respect to income meeting their needs for energy and protein, but fully the bottom half of the income distribution failing to meet needs for vitamin A and riboflavin, as indicators of dietary quality. There have been substantial shifts over the last 15 to 20 years in the food baskets of urban families in particular, in favour of inexpensive dietary energy and decreased diversity and dietary quality. Between 1985 and 1995, urban households increased their bread consumption by almost 25\%, from an average of 355 to 435 g person $^{-1}$ day $^{-1}$. Sugar and fats and oils also showed increases, while dairy products, meat, and fruits and vegetables showed dramatic declines. Consumption of meat and fruits and vegetables declined by almost $50 \%$ each. Rural households showed much less dramatic shifts, other than increases in use of fats, oils and sugars, some decrease in bread, and an increase in rice and dairy products $^{12}$ (Table 5).

Data on household-level food consumption from the national survey in 1995 indicate considerable imbalances, with both under- and over-consumption prevalent ${ }^{2,3}$. Table 6 shows household-level per capita intake nationally relative to Food and Agriculture Organization/World Health Organization (FAO/WHO) recommended intakes: more than one-third of households consume in excess of $120 \%$ of recommendations for nutrients except riboflavin; at the same time $20 \%$ of households consume less than $90 \%$ of recommended energy intake and larger numbers of households had evidently low intakes of several micronutrients. Fat intakes remain fairly low at $22 \%$ of the dietary energy on average, but show the expected urban/rural differential with mean intakes in urban Tehran approaching 30\% of dietary energy. Data from the 1995 National Food Consumption Survey (Table 7) show energy and fat intakes for Iran (nation-wide), Tehran and for three selected provinces - West Azerbaijan as a fairly economically advantaged area, and Sistan/Baluchistan and Kerman as relatively poor provinces.

Table 5 Change in household food basket (expenditure data) for urban and rural areas, 1985-1995 $\left(\right.$ p person $^{-1}$ day $^{-1}$ )

\begin{tabular}{|c|c|c|c|c|}
\hline \multirow[b]{2}{*}{ Food item/group } & \multicolumn{2}{|c|}{$\begin{array}{l}\text { Urban households } \\
\text { (mean) (g person } \\
\text { day }^{-1} \text { ) }\end{array}$} & \multicolumn{2}{|c|}{$\begin{array}{l}\text { Rural households } \\
\text { (mean) }\left(\mathrm{g}_{\text {person }}^{-1}\right. \\
\text { day }^{-1} \text { ) }\end{array}$} \\
\hline & 1985 & 1995 & 1985 & 1995 \\
\hline Bread & 355 & 435 & 561 & 332 \\
\hline Rice & 104 & 107 & 86 & 100 \\
\hline Meat & 138 & 65 & 50 & 58 \\
\hline Dairy products & 182 & 153 & 164 & 203 \\
\hline Eggs & 29 & 22 & 20 & 18 \\
\hline Fruits and vegetables & 755 & 432 & 284 & 334 \\
\hline Fats and oils & 32 & 33 & 18 & 32 \\
\hline Sugar & 41 & 50 & 40 & 60 \\
\hline Total & 1630 & 1297 & 1223 & 1137 \\
\hline
\end{tabular}

Source: Pajouyan ${ }^{12}$. 
Table 6 Per capita food consumption in relation to FAO/WHO recommended levels for selected nutrients, Iran, 1995 (percentage of households)

\begin{tabular}{lcccc}
\hline Nutrient & $\begin{array}{c}<80 \% \text { of recommended } \\
\text { ('severely insecure') (\%) }\end{array}$ & $\begin{array}{c}80-90 \% \text { of recommended } \\
\text { ('mildly insecure') (\%) }\end{array}$ & $\begin{array}{c}\text { 90-110\% of recommended } \\
\text { ('secure') (\%) }\end{array}$ & $\begin{array}{c}>120 \% \text { of recommended } \\
\text { ('over-consumption') (\%) }\end{array}$ \\
\hline Energy & 11 & 9 & 25 & 43 \\
Protein & 8 & 7 & 19 & 55 \\
Calcium & 30 & 10 & 18 & 34 \\
Vitamin A & 46 & 5 & 10 & 34 \\
Vitamin B $B_{2}$ & 70 & 9 & 11 & 7 \\
\hline
\end{tabular}

Source: National Nutrition and Food Technology Research Institute, 1996.

\section{The emergence of obesity and diet-related chronic disease}

In spite of the persistence of malnutrition and the presence of poor dietary quality for many families, obesity and dietrelated chronic diseases are beginning to come on to the public health radar screen in Iran. The combination of cardiovascular and cerebrovascular disease is the leading mortality cause - almost half of all nation-wide mortality; the second leading mortality cause is accidents, followed by respiratory disease and cancer.

The best data sources on chronic disease and risk factors are two large national surveys undertaken by the Ministry of Health and Medical Education in $1990^{13}$ and $1999^{10}$. Table 8 shows the prevalence of overweight and obesity, defined as body mass index (BMI, $\mathrm{kg} \mathrm{m}^{-2}$ ) of 25-29.9 and $\geq 30$, respectively, for adults by rural/urban residence and age in the 1999 survey (height and weight were not measured in the 1990 survey). Twenty-eight per cent of urban women between 40 and 69 years of age are classified as obese, and $15 \%$ of rural women of the same age. Prevalences are lower in men - 11\% for urban and 6\%

Table 7 Median per capita energy intake (kcal) and percentage of dietary energy from fat by rural/urban residence, Iran and selected provinces, 1995

\begin{tabular}{lcc}
\hline Sample & $\begin{array}{c}\text { Median energy } \\
\text { intake (kcal) }\end{array}$ & $\begin{array}{c}\text { Average dietary } \\
\text { energy from fat (\%) }\end{array}$ \\
\hline $\begin{array}{l}\text { National (Iran) } \\
\text { Urban }\end{array}$ & 2444 & 24 \\
Rural & 2836 & 19 \\
$\quad$ Total & 2605 & 22 \\
Tehran & & \\
Urban & 2350 & 30 \\
Rural & 2740 & 26 \\
Total & 2365 & 29 \\
Azarbaijan Gharbi & & \\
Urban & 2594 & 25 \\
Rural & 3105 & 22 \\
$\quad$ Total & 2825 & 23 \\
Sistan/Baluchistan & & \\
Urban & 2397 & 20 \\
Rural & 3040 & 15 \\
Total & 2568 & 17 \\
Kerman & & 23 \\
Urban & 2196 & 26 \\
Rural & 2455 & 20 \\
Total & 2307 & \\
\hline
\end{tabular}

Source: National Nutrition and Food Technology Research Institute, 1995. for rural men of the same age. Data from the same survey (Table 4) show that about $10 \%$ of urban and $7 \%$ of rural pre-school children are overweight. Examination of the occurrence within households of obesity in adult women and malnutrition (defined as underweight) in young children revealed that households in which the youngest woman was obese were significantly less likely than other households to have an underweight 2-year-old child.

A 1995 study of 1000 households in urban Tehran ${ }^{14}$ found $55 \%$ of women and $38 \%$ of men, aged 16 years and older, to be overweight or obese $\left(\mathrm{BMI}>25 \mathrm{~kg} \mathrm{~m}^{-2}\right)$. Overweight and obesity characterised as many highincome as low-income households. For both men and women, age was positively associated with risk of overweight; for men, education had a positive relationship to overweight, but for women the opposite was true (i.e. less-educated women were more likely to be overweight than better-educated women).

Table 9 shows the prevalence of elevated serum cholesterol levels (total cholesterol $>200 \mathrm{mg} \mathrm{dl}^{-1}$ ) for adults in the national health surveys for 1990 and 1999. More than a third of middle-aged adults and $20-27 \%$ of young adults show elevated levels, with little difference between men and women or by rural/urban residence. Blood pressure was measured in both surveys, and shows a rise in prevalence of hypertension over the time period. In 1990, $13.2 \%$ of men and $18.5 \%$ of women, aged 40-69 years, in urban areas had diastolic blood pressure $>90 \mathrm{mmHg}$; in 1999 the prevalences were 18.3\% for men and $20.9 \%$ for women. Rural men and women showed similar trends in blood pressure. While self-reported diagnosed chronic illness ('Has a doctor ever told you that you have xxx?') is clearly underreported, the two surveys show rising proportions of adults who know that they have hypertension and diabetes mellitus. Prevalences of known diabetes and hypertension in both urban men and women approximately doubled between 1990 and 1999; in $1999,3 \%$ of urban men and $6.5 \%$ of urban women reported having high blood pressure, and $1.4 \%$ of men and $2.5 \%$ of women reported having diabetes.

\section{Summary and policy implications}

Although Iran appears to be early in the 'nutrition transition' that characterises so much of the world, obesity 
Table 8 Prevalences (\%) of overweight and obesity (BMI of $25-29.9$ and $\geq 30 \mathrm{~kg} \mathrm{~m}^{-2}$, respectively) among adults by age and rural/urban residence; Iran National Health Survey, 1999

\begin{tabular}{|c|c|c|c|c|}
\hline \multirow[b]{3}{*}{ Adult category } & \multicolumn{4}{|c|}{ Prevalence (\%) } \\
\hline & \multicolumn{2}{|c|}{ Urban } & \multicolumn{2}{|c|}{ Rural } \\
\hline & Overweight & Obesity & Overweight & Obesity \\
\hline \multicolumn{5}{|l|}{ Women } \\
\hline $15-39$ years $(n=13185)$ & 24.5 & 12.3 & 18.5 & 6.9 \\
\hline $40-69$ years $(n=5534)$ & 38.9 & 27.9 & 31.3 & 15.6 \\
\hline $70+$ years $(n=877)$ & 30.4 & 15.6 & 21.6 & 6.7 \\
\hline \multicolumn{5}{|l|}{ Men } \\
\hline $15-39$ years $(n=10029)$ & 21.2 & 4.7 & 14.3 & 2.2 \\
\hline $40-69$ years $(n=4746)$ & 39.8 & 11.0 & 22.5 & 6.2 \\
\hline $70+$ years $(n=953)$ & 28.5 & 5.7 & 16.5 & 3.0 \\
\hline
\end{tabular}

and obesity-related chronic disease are clearly emerging, particularly in urban areas (which will comprise $80 \%$ of the population in another 20 years) and among women. In Iran, this is occurring in the absence of significant economic improvement for most families, and in the presence of severe constraints to dietary quality for the poorer half of the population. Unfortunately, there are no systematic data available on changes in physical activity over time in this population. However, there are a number of forces that operate to encourage minimisation of physical activity, particularly for women. Public transport systems are generally not well developed in the cities, forcing reliance on private automobiles and taxis by many. Investment in education has resulted in more years' attendance in school, and a higher proportion of adults in white-collar and professional occupations and fewer in occupations that require regular physical exertion. The information revolution has brought computers and Internet coffee houses to Iran as elsewhere, and television access is widespread. And probably important, strict social policies regarding the separation of men and women and proper attire for women in public have essentially resulted in the privatisation of social events, particularly in cities. Gatherings of friends and family tend to be held in the

Table 9 Prevalence (\%) of total cholesterol $>200 \mathrm{mg} \mathrm{dl}^{-1}$ for men and women by age and rural/urban residence; Iran National Health Survey, 1990 and 1999

\begin{tabular}{lccccc}
\hline & \multicolumn{4}{c}{ Prevalence (\%) } \\
\cline { 2 - 4 } & \multicolumn{2}{c}{ Urban } & & \multicolumn{2}{c}{ Rural } \\
\cline { 2 - 4 } Category & 1990 & 1999 & & 1990 & 1999 \\
\hline Men & & & & \\
15-39 years & 24.0 & 21.8 & 22.7 & 19.3 \\
40-69 years & 40.2 & 39.9 & 36.4 & 31.9 \\
$70+$ years & - & 34.3 & - & 28.1 \\
Women & 26.0 & 26.2 & & 26.8 & 20.6 \\
15-39 years & 47.8 & 48.5 & 41.2 & 38.7 \\
40-69 years & - & 50.9 & - & 41.2 \\
$70+$ years & - & &
\end{tabular}

privacy of homes, accompanied with food but not with the opportunity for physical activity.

In summary, urbanisation, population growth, major shifts in diets and, in all probability, reduced physical activity have put an accelerated nutrition transition into motion during the 1980s and the predictable health effects have emerged during the 1990s. The dietary profile over the last two decades has been influenced on the one hand by untargeted subsidies for dietary energy and on the other by continuously rising food prices. The important results are access to adequate dietary energy by $80 \%$ of households, but a dietary pattern characterised by overconsumption at higher income levels and low nutrient density across the board. A recent analysis showed that households in the top 30\% of per capita income benefit two to three times as much from food subsidies compared with households in the bottom third of the income distribution. A 1995 study in Tehran ${ }^{14}$ showed that among households in the upper $50 \%$ of income, where income is no constraint to diet, satisfaction of needs for key nutrients in the diet was only possible at energy levels of $3000 \mathrm{kcal} \mathrm{day}^{-1}$. In other words, low nutrient density is not entirely an income-driven issue.

What are the key policy options? A well-designed and carefully managed population policy is in place, but population growth will continue through the next several years as today's cohort of adolescents enters adulthood. Urbanisation will also continue, albeit at a somewhat slower pace than in the last few years; more than half of the current population is young and will enter the workforce in the next decade, largely in non-agricultural occupations. A comprehensive national policy on food, diet and lifestyle is required, ideally including:

1. modification of current agricultural policy to take into account factors in addition to dietary energy (i.e. wheat) supply;

2. a national programme to promote nutritional literacy, with specific focus on schools and households at risk of malnutrition; 
3. targeting and modification of food subsidies; and

4. integration of health, diet-related and sports programmes.

The constraints to the design and implementation of such policies include limitations in expertise, institutional capacity, the policy environment, and low levels of investment. A recent national study in this area ${ }^{2}$ has been instrumental in finding a place for food and nutrition security issues within the Third National Development Plan and a few important beginnings have already been made.

\section{Acknowledgements}

The able technical assistance of Nasrin Omidvar, Azam Khatam, Hormozd Hormozdyari, Sharzad Rokni and Hossein Mazloumi is gratefully acknowledged.

\section{References}

1 Islamic Republic of Iran. Country Report on Population, Reproductive Health and Family Planning Program in the Islamic Republic of Iran. Tehran: Islamic Republic of Iran, February 1998.

2 Ghassemi H. Food and Nutrition Security in Iran: A Study on Planning and Administration. Tehran: Plan and Budget Organization, Islamic Republic of Iran, April 1997 [original in Persian, English translation dated September 1997].

3 Ghassemi H. National Food and Nutrition Security: A Note on Planning and Administration. Tehran: Food and Agriculture Organization of the United Nations, representation in the Islamic Republic of Iran, 2000.
4 Food and Agriculture Organization of the United Nations (FAO). The State of Food and Agriculture 1998. FAO Agriculture Series No. 31. Rome: FAO, 1998.

5 United Nations Development Program (UNDP). Human Development Report 2000. New York: UNDP, 2001.

6 The World Bank. World Development Indicators 1998. Washington, DC: The World Bank, 1999.

7 Zoonoz FB. In: Rais Dana F, ed. Poverty in Iran. Proceedings of a Seminar, Behzisti University, Tehran, 2000.

8 United Nations Children's Fund (UNICEF)/Tehran. Overcoming Iodine Deficiency in the Islamic Republic of Iran. Tehran: UNICEF/Tehran, 2000.

9 Ministry of Health and Medical Education and United Nations Children's Fund (UNICEF)/Tehran. The Multiple Health Indicator Cluster Survey of the Islamic Republic of Iran, 23-27 September 1995. Tehran: UNICEF/Tehran, 1996.

10 Nour Balaa AA, Mohammad K. Second National Health Survey in the Islamic Republic of Iran. Tehran: Ministry of Health and Medical Education, Undersecretary for Research, 2001.

11 Omidvar N, Ghazi-Tabatabie M, Harrison GG, Egtesadi S, Mahboob S, Pourbakht M. Development and validation of a food frequency questionnaire for screening vitamin A status in women of childbearing age in northwestern Iran. Food Nutr. Bull. [in press].

12 Pajouyan J. In: Ghassemi H. Food and Nutrition Security in Iran: A National Study on Planning and Administration. Tehran: Plan and Budget Organization, Islamic Republic of Iran, 1998.

13 Zali MR, Mohammad K, Masdjedi MR. National Health Survey in the Islamic Republic of Iran. Tehran: Ministry of Health and Medical Education, Undersecretary for Research Affairs, 1993.

14 Ghassemi H, Kimiagar M, Koupahi M. Food and Nutrition Security in Tehran Province. Tehran: National Institute of Nutrition and Food Technology, 1996. 